\title{
Gamma Ray and FTIR Studies in Zinc Doped Lead Borate Glasses for Radiation Shielding Application
}

\author{
Zakiyyu Ibrahim Takai ${ }^{a, b, c} *$, Rajinder Singh Kaundal ${ }^{d}$, Mohd Kamarulzaki Mustafa ${ }^{a, b}$, \\ Saliza Asman ${ }^{b}$, Aisha Idris, Yusuf Shehu ${ }^{e}$, Jibrin Mohammad ${ }^{d, f}$, Miftahu Gambo Idris ${ }^{g}$, Mansur Said $^{c}$ \\ ${ }^{a}$ Microelectronic and Nanotechnology-Shamsuddin Research Centre - Mint-SRC, Universiti Tun Hussein \\ Onn Malaysia - UTHM, Batu Pahat, Johor Bahru 86400, Malaysia \\ ${ }^{b}$ Department of Physics and Chemistry, Faculty of Applied Sciences and Technology, Universiti Tun \\ Hussein Onn Malaysia, Pagoh Educational Hub, 86400, Muar, Johor, Malaysia \\ 'Department of Physics, Faculty of Science Yusuf, Maitama Sule University, Kano, Nigeria \\ ${ }^{d}$ Department of Physics, Lovely Professional University, Jalandhar, India \\ ${ }^{e}$ Department of Physics, Faculty of Science, Kano State University of Science and Technology, Nigeria \\ ${ }^{f}$ Department of Physics, Faculty of Science, Federal University Dutse, Jigawa State, Nigeria \\ ${ }^{g}$ Department of Physics, Faculty of Science, Yobe State University, Nigeria
}

Received: June 09, 2018; Revised: September 13, 2018; Accepted: October 04, 2018

\begin{abstract}
Gamma ray shielding properties of borate glass samples containing oxides of lead and zinc are prepared by melt and quench technique and evaluated theoretically using XCOM computer software for gamma ray shielding properties. However, gamma ray shielding properties are discussed in terms of various calculated parameters such as half value layer, mean free path and mass attenuation coefficient. The calculated parameters are compared by the author with conventional shielding material concrete. FTIR studies are undertaken to investigate the various structural groups present in the prepared system. Furthermore, it was observed that the glass sample S1 posses minimum HVL value and maximum mass attenuation coefficient, It has been inferred that addition of lead improve the gamma ray shielding properties and simultaneously decrease the rigidity of the glass systems due to formation of non bridging oxygen. Gamma ray shielding properties of our glass systems have been compared with standard nuclear radiation shielding concrete.
\end{abstract}

Keywords: glass, FTIR, mass attenuation coefficients, mean free path, half value layer.

\section{Introduction}

Recent advancement of nanotechnology has made nanoscience hot area of research due to their infinite number of advantageous properties. Beside, the focused have been made on gamma ray radiation for different purposes, including nuclear reactor, medicine, industries and nuclear power plant. In recent years transition metal oxide glasses have attracted greatly the attention of many researchers and industries because of their valuable optical and electrical properties ${ }^{1}$. Heavy metal glasses containing boron oxide $\left(\mathrm{B}_{2} \mathrm{O}_{3}\right)$ as a glass former are of great technological importance because of their wider range of their applications ${ }^{2}$.

These glasses find their use in various applications including lightening, laboratory, cookware, medical, LCD screens and glass wool for thermal and acoustic insulation ${ }^{3}$. Borosilicate glasses containing lead is of great importance because it possesses desirable electrical resistivity, low melting points, high chemical stability over a wider range of concentrations ${ }^{4}$. Furthermore, these glasses play vital role in wide area of research and industrial applications related to enamels, solder glasses, semiconductor microelectronics glass, ceramic cements and in nuclear waste immobilization ${ }^{5}$.

In recent time, the study of borate glass in particular, as one the major essential glass former, once it incorporated with certain amount of heavy metal such as lead oxide and zinc oxide its properties such as hardness, mechanical strength, transparency and optical properties, drastically change $e^{(4,5)}$. These $\mathrm{B}_{2} \mathrm{O}_{3}$ glasses is one of the form major glass former due to its higher bond strength, that make them promising candidate for feature shielding materials.

Usually, concrete are used as conventional shielding materials for protection of gamma radiations but due to certain limitations in the concrete like zero visibility and degradation of their mechanical strength in harsh environmental conditions, researchers requires some alternative method to replace it with another material with higher transference, mechanical strength and non-degradable ${ }^{6}$. Nowadays, borate and silicate glasses containing heavy metals becoming promising candidates as a radiation shielding materials.

The aim of present work is to investigate radiationshielding properties of some lead and Zinc based glasses and their structural properties using FTIR investigations. 


\section{Experimental and Theoretical Techniques}

All the synthesis chemical reagent of the glass was analytic grade used without further purification. The shielding glass sample was prepared via assisted melt quenching method as followed. A number of $\mathrm{Pb}_{3} \mathrm{O}_{4}, \mathrm{ZnO}$, and $\mathrm{H}_{3} \mathrm{BO}_{3}$ were thoroughly mixed together. The homogenous mixture was subsequently place in the furnace for a period of $2 \mathrm{~h}$ at 800 ${ }^{\circ} \mathrm{C}$. The melt glass samples were rapidly cooled to room temperature. The glass sample's density was calculated using Archimedes principal benzene solution are used as immersion liquid. Furthermore, the molecular structure of the glass matrix were analyzed using Fourier Transformation Infrared spectrum (FTIR) (Perkin Elmer Spectrum 100 FTIR spectrometer)

The mass attenuation coefficient of the prepared glass samples have been investigated theoretically using Win XCOM computer software at different energies, and compare with standard shielding materials concrete ${ }^{7,8}$.

Molar volume $\left(\mathrm{V}_{\mathrm{m}}\right)$ volume of the glass samples has been estimated by using the following expression:

$$
V_{m}=M / \rho
$$

Where $\rho$ is the density of the sample and $M$ is the molecular weight of the sample. The mass attenuation coefficients calculated using the equation (1)

$$
\mu_{m}=\sum_{i}^{n} w_{i(\mu / \rho)}
$$

Where $w_{i}$ is the weight and $(\mu / \rho)$ is the mass attenuation coefficient of the sample. The $(\mu / \rho)$ values can be taken directly from XCOM software or user-friendly Win XCOM software after substituting the sample composition. The linear attenuation coefficient (in $\left.\mathrm{cm}^{-1}\right)$ is multiplication of $\mu_{\mathrm{m}}=(\mu / \rho)$ value and density of the glass. One the easiest technique to determine the effectiveness of material toward the radiation shielding is to employ the idea of half value layer (HVL). This concept was defined by many researchers as the quantity of radiation shielding material needed to reduce the radiation intensity to one-half of the unshielded valve ${ }^{7}$.

$$
H V L=(0.693 / \mu)
$$

Where $\mu$ represent the linear attenuation coefficient and it can be found in the tabular form of radiation shielding parameter. In order to determine the attenuated energy phone in the absorbing medium, the Mean free path (MFP) was estimated as the distance in which the initial photon intensity can be reduced by $1 / \mathrm{e}$ factor. Therefore, mean free path (MFP) is considered as the reciprocal of the linear attenuation coefficient ${ }^{8}$.

$$
(M F P)=(1 / \mu)
$$

\section{Result and Discussion}

\subsection{Densities and molar volume}

The molar volume of the glass samples was calculated using equation 1 . However, Table 1 contains the chemical composites of the prepared glass samples, densities and molar volume. Furthermore, it was observed that the density of the glass sample increases with increase of heavy metal content (lead oxide), the molar volume of the glass samples also increases with increase in concentration of these heavy metal oxides. The molar volume clearly shows that the prepared glass sample's structure corresponding to higher lead composition is becoming more open leading the formation

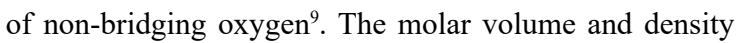
the glass samples corresponding to low lead compositions decreases due to decreases of heavy metal content.

\subsection{Mean free path and mass attenuation coefficient}

The estimated values of men free path (MFP) for all the samples are given in Table 2. From Table 2 it can be concluded that sample S4 has the lowest mean free path at high energy, which means the rate at which the photon energy is penetrating the sample is less in samples S4. Furthermore, the values of mean free path increase with the increase in the energy of incident Photon ${ }^{12}$.

The glass samples were effectively prepared and its mass

\begin{tabular}{|c|c|c|c|c|c|}
\hline \multirow{2}{*}{$\begin{array}{l}\text { Name of } \\
\text { Sample }\end{array}$} & \multicolumn{3}{|c|}{ Compositions } & \multirow{2}{*}{$\begin{array}{c}\text { Sample } \\
\text { Density }(\mathrm{g} / \\
\left.\mathrm{cm}^{3}\right)\end{array}$} & \multirow{2}{*}{$\begin{array}{c}\text { Molar } \\
\text { Volume } \\
\left(\mathrm{cm}^{3} / \mathrm{mol}\right)\end{array}$} \\
\hline & PbO & $\mathrm{ZnO}$ & $\mathrm{B}_{2} \mathrm{O}_{3}$ & & \\
\hline $\mathrm{S} 1$ & 20 & 0 & 80 & 3.75 & 26.75584 \\
\hline $\mathrm{S} 2$ & 10 & 0 & 90 & 3.39 & 25.06729 \\
\hline $\mathrm{S} 3$ & 5 & 5 & 90 & 3.35 & 23.25004 \\
\hline S4 & 0 & 10 & 90 & 3.25 & 21.78373 \\
\hline
\end{tabular}
attenuation coefficient was evaluated using equation 2 , and the results were given in the Table 3 , at the energy ranging

Table 1. Composites chemicals, density ( $\rho)$, molar volume (vm)

Table 2. Theoretical Result of Mean Free Path

\begin{tabular}{lcccc}
\hline \multicolumn{5}{c}{ Mean Free Path $(\mathrm{cm})$} \\
\hline Energy & S1 & S2 & S3 & S4 \\
\hline $1.00 \mathrm{E}-03$ & $6.3 \mathrm{E}-05$ & $7.43 \mathrm{E}-05$ & $8.06 \mathrm{E}-05$ & $9.09 \mathrm{E}-05$ \\
$1.00 \mathrm{E}-02$ & $4.71 \mathrm{E}-03$ & $8.36 \mathrm{E}-03$ & $9.66 \mathrm{E}-03$ & $1.20 \mathrm{E}-02$ \\
$1.00 \mathrm{E}-01$ & $1.12 \mathrm{E}-01$ & $2.01 \mathrm{E}-01$ & $3.38 \mathrm{E}-01$ & $1.69 \mathrm{E}+00$ \\
$1.00 \mathrm{E}+00$ & $4.05 \mathrm{E}+00$ & $4.58 \mathrm{E}+00$ & $4.72 \mathrm{E}+00$ & $4.96 \mathrm{E}+00$ \\
$1.00 \mathrm{E}+01$ & $8.28 \mathrm{E}+00$ & $1.09 \mathrm{E}+01$ & $1.23 \mathrm{E}+01$ & $1.47 \mathrm{E}+01$ \\
$1.00 \mathrm{E}+02$ & $5.56 \mathrm{E}+00$ & $8.45 \mathrm{E}+00$ & $1.08 \mathrm{E}+01$ & $1.61 \mathrm{E}+01$ \\
$1.00 \mathrm{E}+03$ & $4.56 \mathrm{E}+00$ & $6.97 \mathrm{E}+00$ & $8.94 \mathrm{E}+00$ & $1.36 \mathrm{E}+01$ \\
$1.00 \mathrm{E}+04$ & $4.38 \mathrm{E}+00$ & $6.70 \mathrm{E}+00$ & $8.58 \mathrm{E}+00$ & $1.30 \mathrm{E}+01$ \\
$1.00 \mathrm{E}+05$ & $4.36 \mathrm{E}+00$ & $6.65 \mathrm{E}+00$ & $8.52 \mathrm{E}+00$ & $1.29 \mathrm{E}+01$ \\
\hline
\end{tabular}


Table 3. Mass Attenuation Coefficients $(\mu \mathrm{m})$ of Glass Sample

\begin{tabular}{lccccccccc}
\hline Sample & \multicolumn{7}{c}{ Mass Attenuation Coefficient $\left(\mathbf{c m}^{2} \mathbf{g}^{-1}\right)$} \\
\hline Energy & $\mathbf{1 . 0 0 E}-\mathbf{0 3}$ & $\mathbf{1 . 0 0 E}-\mathbf{0 2}$ & $\mathbf{1 . 0 0 E}-\mathbf{0 1}$ & $\mathbf{1 . 0 0 E}+\mathbf{0 0}$ & $\mathbf{1 . 0 0 E}+\mathbf{0 1}$ & $\mathbf{1 . 0 0 E}+\mathbf{0 2}$ & $\mathbf{1 . 0 0 E}+\mathbf{0 3}$ & $\mathbf{1 . 0 0 E}+\mathbf{0 4}$ & $\mathbf{1 . 0 0 E}+\mathbf{0 5}$ \\
S1 & $1.60 \mathrm{E}+04$ & $2.12 \mathrm{E}+02$ & $8.93 \mathrm{E}+00$ & $2.47 \mathrm{E}-01$ & $1.21 \mathrm{E}-01$ & $1.80 \mathrm{E}-01$ & $2.19 \mathrm{E}-01$ & $2.28 \mathrm{E}-01$ & $2.30 \mathrm{E}-01$ \\
S2 & $1.35 \mathrm{E}+04$ & $1.20 \mathrm{E}+02$ & $4.97 \mathrm{E}+00$ & $2.18 \mathrm{E}-01$ & $9.20 \mathrm{E}-01$ & $1.18 \mathrm{E}-01$ & $1.43 \mathrm{E}-01$ & $1.49 \mathrm{E}-01$ & $1.50 \mathrm{E}-01$ \\
S3 & $1.24 \mathrm{E}+04$ & $1.04 \mathrm{E}+02$ & $2.96 \mathrm{E}+00$ & $2.12 \mathrm{E}-01$ & $8.16 \mathrm{E}-01$ & $9.28 \mathrm{E}-01$ & $1.12 \mathrm{E}-01$ & $1.17 \mathrm{E}-01$ & $1.17 \mathrm{E}-01$ \\
S4 & $1.10 \mathrm{E}+04$ & $8.33 \mathrm{E}+01$ & $5.92 \mathrm{E}-01$ & $2.02 \mathrm{E}-01$ & $6.82 \mathrm{E}-01$ & $6.20 \mathrm{E}-01$ & $7.38 \mathrm{E}-01$ & $7.71 \mathrm{E}-01$ & $7.76 \mathrm{E}-01$ \\
\hline
\end{tabular}

from $1 \mathrm{meV}$ to $100 \mathrm{keV}$. It has clearly observed that to some very extent, the values of mass attenuation are quite very high at low energy value; at this stage, the photoelectric effect is dominant. The mass attenuation coefficient value is evident in the Tables 3, which shows high decease in attaining minimum values at the intermediate energy range. Some photon energy move away from the intermediate range of energy are consider as Compton scattering region, the high range of energy corresponding to pair production values of mass attenuation coefficient, at very high energy the value of mass attenuation coefficient become almost constant $t^{6,10}$.

\subsection{Half Value Layer and FTIR Analysis}

Half Value Layer (HVL) of the prepared glass samples at different energies was calculated from linear attenuation coefficient using equation 3 is shown in Figure 1. The simplest method to investigate the effectiveness of material is to compute its HVL value. It can be observed from Fig 1 that the HVL that was found with minimum values among

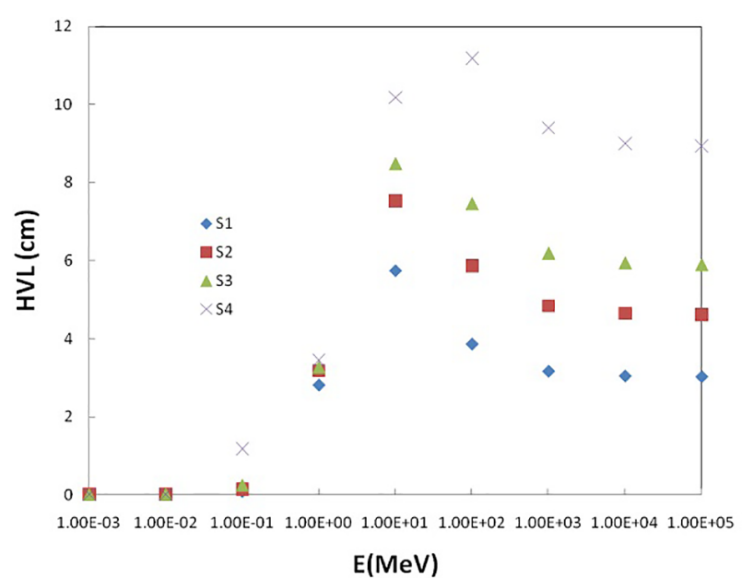

Figure 1. Plot of HVL $(\mathrm{cm})$ for various samples as a function of photon energy the glass samples is $\mathrm{S} 1$, which corresponds to highest lead composition (see Table 1). Minimum HVL value suggested that this composition is more effective for gamma ray shielding applications ${ }^{11}$. Therefore, the HVL of S1 can be compared with corresponding HVL of the conventional shielding materials concrete (from table 4). The compositions table for the chosen concrete materials ordinary and barite concrete are given in Table 4.

The sample S1 that has minimum HVL value among all the prepared samples is plotted with corresponding HVL of standard shielding materials concrete, keeping this in mind that this glass sample (S1) is chosen and its HVL is compared with ordinary and barite concrete as shown in Figure 2. From Figure 2 it can be concluded that the sample S1 has lowest values as compared with ordinary or barite concrete. Therefore, $\mathrm{S} 1$ is more effective to be used be use for radiation shielding then concrete materials ${ }^{7}$.

The IR spectral studies (Figure 3) have been undertaken to investigate various structural groups present in our glass samples. The peaks in Figure 3 corresponding to wave numbers $545.87 \mathrm{~cm}^{-1}, 653.89 \mathrm{~cm}^{-1}, 785.05 \mathrm{~cm}^{-1}$ are assigned to the stretching vibration in the symmetrical of $\mathrm{PbO}_{3}$ and $\mathrm{ZnO}$ spectral unit ${ }^{10}$. Some peaks are observed at $885.36 \mathrm{~cm}^{-1}$ it was shifted strongly to the high wave number indicating presence of $\mathrm{Pb}-\mathrm{O}$ group in the sample ${ }^{13}$.

The peaks that were appear between $1344.7 \mathrm{~cm}^{-1}$ to $1749.96 \mathrm{~cm}^{-1}$ is assigned to the bond of various vibrations stretching in the borate functional unit assigned at $\mathrm{BO}_{3}$ units. The oxygen bridges appear between one tetrahedral and one trigonal boron ${ }^{14}$. The peaks at 2364.5 to $2371.2 \mathrm{~cm}^{-1}$, are due to $\mathrm{B}-\mathrm{O}$ symmetric stretching vibration in $\mathrm{BO}_{3}$ units from Pyro and Ortho borate groups, these are highest intensity bands ${ }^{15}$. Some peaks are also observed with higher wavenumber in range of 3228.9 to $3458.5 \mathrm{~cm}^{-1}$ can be assigned to $\mathrm{OH}$ group of element or $\mathrm{H}_{2} \mathrm{O}$.

Table 4. Chemical Compositions of Concretes

\begin{tabular}{|c|c|c|c|c|c|c|c|c|c|c|c|c|c|c|c|}
\hline \multirow{2}{*}{ Concrete } & \multicolumn{14}{|c|}{ Weight Fraction } & \multirow{2}{*}{ Density } \\
\hline & $\boldsymbol{H}$ & $\boldsymbol{B}$ & $C$ & $O$ & $N a$ & $M g$ & $A l$ & $S i$ & $S$ & $K$ & $C a$ & $\mathrm{Cr}$ & $F r$ & $B a$ & \\
\hline \multirow{2}{*}{ Barite } & 0.0 & 0.01 & & 0.34 & & 0.002 & 0.004 & 0.01 & 0.099 & & 0.0 & & 0.004 & 0.42 & \multirow{2}{*}{3.5} \\
\hline & 08 & 2 & & 8 & & 2 & 4 & 5 & 7 & & 8 & & 7 & 4 & \\
\hline \multirow{2}{*}{ Ordinary } & \multirow{2}{*}{0.1} & & 0 & 0.52 & 0.01 & \multirow{2}{*}{0.002} & 0.033 & 0.33 & & 0.0 & 0.0 & \multirow{2}{*}{\multicolumn{2}{|c|}{0.014}} & & \multirow{2}{*}{2.3} \\
\hline & & & & 9 & 6 & & 8 & 7 & & 1 & 4 & & & & \\
\hline
\end{tabular}




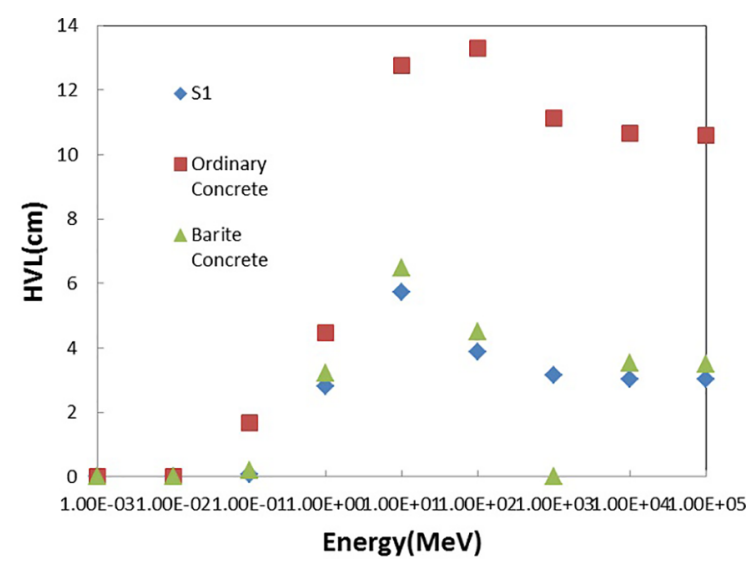

Figure 2. Plot of HVL (cm) for S1 and ordinary and barite concretes as a function of photon energy

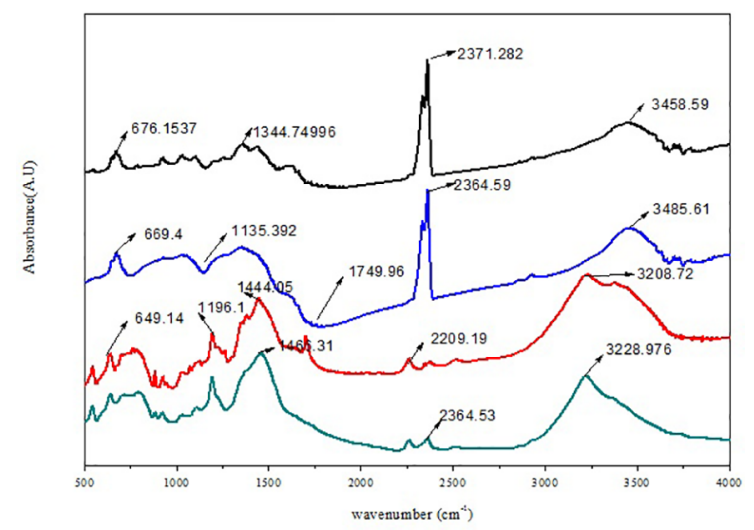

Figure 3. FTIR spectra of prepared glass samples

\section{Conclusions}

In this work, it is concluded that glass sample S1 has maximum mass attenuation coefficient and minimum HVL value. Furthermore, it is concluded that the attenuation properties improves with increase in lead to borate ratio. The samples containing lead shown better shielding properties in terms of less HVL value and high mass attenuation coefficient as compared with ordinary and barite concrete. FTIR studies indicate the coexistence of trigonal $\mathrm{BO}_{3}$ and tetrahedral $\mathrm{BO}_{4}$ units. The influence of heavy metal oxide $\mathrm{PbO}$ on the structural changes in borate glasses can be attributed to transformation of $\mathrm{PbO}$ to $\mathrm{PbO}_{4}$ structural groups in the glass structure. Our findings suggest that glasses containing lead can serve as good radiation shielding materials as compared to concretes.

\section{Acknowledgement}

This research was supported by Yusuf Maitama Sule University, Kano. The author thanks Lovely Professional University India for given atmosphere to conduct FTIR study.

\section{References}

1. El-Kheshen AA, El-Batal FH, Marzouk SY. UV-visible, infrared and Raman spectroscopic and thermal studies of tungsten doped lead borate glasses and the effect of ionizing gamma irradiation. Indian Journal of Pure and Applied Physics. 2008;46(4):225-238.

2. Kaur M, Singh SP, Mudahar DS, Mudahar GS. Structural investigation of $\mathrm{B}_{2} \mathrm{O}_{3}-\mathrm{li}_{2} \mathrm{CO}_{3}-\mathrm{Al}_{2} \mathrm{O}_{3}$ glasses by molar volume measurements and ftir spectroscopy. Materials Physics and Mechanics. 2012;15:66-73.

3. Prasad YDS, Rao AV, Srikanth K, Emmanuel KA. Spectroscopic and magnetic properties as probe in the structural study of $\mathrm{PbO}$ $\mathrm{ZnO}-\mathrm{B}_{2} \mathrm{O}_{3}$ glass system doped with $\mathrm{MnO}$. Rasayan Journal of Chemistry. 2011;4(2):358-370.

4. MacFarlane DR, Newman PJ, Plathe R, Booth DJ. Heavy metal oxide glasses as active materials. In: SPIE Conference of Infrared Optical Fibers and Their Applications; 2012 Sep; Boston, MA, USA.

5. Saddeek YB, Bashier SA, Bakr SA. Theoretical analysis of constants of elasticity of lead calcium alumino borosilicate glass system. Glass Physics and Chemistry. 2012;38(5):437-443.

6. Kaur S, Singh KJ. Comparative Study of Lead Borate and Lead Silicate Glass Systems Doped With Aluminum Oxide as Gamma-Ray Shielding Materials. International Journal of Innovative Technology and Exploring Engineering. 2013;25(5):172-175.

7. Atta ER, Zakaria KM, Madbouly AM. Research article study on polymer clay layered nanocomposites as shielding materials for ionizing radiation. International Journal of Recent Scientific Research. 2015;6(5):4263-4269.

8. Kaundal RS, Takai ZI. Comparative Study of attenuation properties of some ternary borate glass systems. Journal of Experimental \& Theoretical Nanotechnology Specialized Researches. 2017;1(3):149157.

9. Gautam C, Yadav AK, Singh AK. AReview on Infrared Spectroscopy of Borate Glasses with Effects of Different Additives. ISRN Ceramics. 2012;2012:428497.

10. Gupta S, Sidhu GS. Measurement of Total and Partial Mass Attenuation Coefficients of Oxide Glasses. International Journal of Modern Engineering and Research. 2013;3(6):3830-3835.

11. Bootjomchai C, Laopaiboon J, Yenchai C, Laopaiboon R. Gamma-ray shielding and structural properties of barium - bismuth - borosilicate glasses. Radiation Physics and Chemistry. 2015;81(7):785-790.

12. Mostafa AG, Saudi HA, Hassaan MY, Salem SM, Mohammad SS. Studies on the Shielding Properties of Transparent Glasses Prepared from Rice Husk Silica. American Journal of Modern Physics. 2015;4(4):149-157.

13. Kaur R, Singh $\mathrm{S}$, Pandey OP. Structural variation in gamma ray irradiated $\mathrm{PbO}-\mathrm{Na}_{2} \mathrm{O}-\mathrm{B}_{2} \mathrm{O}_{3}-\mathrm{SiO}_{2}$ glasses. Solid State Communications. 2014;188:40-44.

14. Pinho S, Ladeiro B. Phytotoxicity by Lead as Heavy Metal Focus on Oxidative Stress. Journal of Botanic. 2012;2012:369572.

15. Boda R, Srinivas G, Komaraiah D, Shareefuddin M, Chary MM, Sayanna R. UV-Vis Absorption and Structural Studies of $\mathrm{Eu}^{3+}$ Ions Doped Alkali Zinc Bismuth Borate Glasses. International Journal of Innovative Research in Science, Engineering and Technology. 2015;4(8):7044-7051. 